\title{
Fostering disaster mitigation through community participation- case of Kochi residents following the Kerala floods of 2018 and 2019
}

\author{
Sameer Ali $^{1}$ (D) Abraham George ${ }^{1}$
}

Received: 18 June 2021 / Accepted: 22 September 2021 / Published online: 4 October 2021

(c) The Author(s), under exclusive licence to Springer Nature B.V. 2021

\begin{abstract}
Community participation has grown in prominence in mitigating disasters globally. It involves the active involvement in search and rescue to reconstruction that people affected by disasters undertake unsolicited. Predictive power in disaster recovery has further increased its relevance. However, quantitative analysis that community participation has on disaster mitigation measures is scant. The study analyses community participation's impact on disaster mitigation measures following the Kochi flood of 2018 and 2019 in India. We use a Multivariate Probit Regression model with a sample size of 750 to analyse the relationship between disaster mitigation measures (namely, disaster event planning, previous experience, following disaster-related news closely, and neighbourhood relationship) and community participation. The results show participants who were active in community events were $23 \%$ more likely to adopt all the disaster mitigation measures than those who did not. In addition, households with special needs members were more likely to be prepared for an unanticipated event. The results also showed higher education levels directly correlated to implementing more significant disaster mitigation measures. Implications for government policy formation include schemes to enhance community rehabilitation and promote social participation to mitigate future disaster events.
\end{abstract}

Keywords Community participation - Disaster mitigation - Multivariate probit regression · Flood $\cdot$ Kerala

\section{Introduction}

The world has been experiencing disasters since humanity existed. It has now become part and parcel of humankind. Coping with these disasters is not a choice anymore but has become the need of the hour. In 2019 alone, the world experienced 396 disasters (CRED

Sameer Ali

sameer_aaa@live.com

Abraham George

abrahamiitkgp@gmail.com

1 Department of Architecture and Planning, IIT Kharagpur, Kharagpur, West Bengal 721302, India 
2020). Out of this, floods recorded the highest number, with 194 occurrences worldwide taking at least 5110 lives (CRED 2020). India topped the mortality count with 1900 casualties (CRED 2020). Due to frequent disasters, many international agencies have considered disaster mitigation their central theme to curb its impacts (Nations 2005).

Disaster mitigation can occur across various scales, from global to regional to urban to community and individual scale (Ali and George 2021). At the personal level, emergency preparedness helps people respond to a disaster appropriately that helps them cope with the after-effects (Henry et al. 2003). However, disaster mitigation is not an individual effort. Governmental organisations and NGOs may formulate mitigating strategies in the event of a disaster. Still, the effectiveness of such measures depends on community involvement through participation/partnership and effective communication (Shaw 2012). Several recent pieces of the literature have focused on community participation as a critical element in disaster mitigation. Its prominence has risen globally due to increasing disasters and viral epidemics/pandemics (Abunyewah et al. 2020; Ada and Bolat 2010; Aldrich 2011a, 2012; Koh and Cadigan 2008). It helps share resources and expertise, and transmission of information leads to greater disaster mitigation and effective responses (Abunyewah et al. 2020; Crabbé and Robin 2006; Ford et al. 2006; Javadinejad et al. 2021; Ostad-AliAskar et al. 2018; Rayamajhee et al. 2021; Tompkins 2005).

In the disaster management domain, the World Health Organisation (WHO) describes community participation as,

Community participation is the active involvement of people from communities preparing for, or reacting to, disasters. True participation means the involvement of the people concerned in analysis, decision-making, planning, and programme implementation, as well as in all the activities, from search and rescue to reconstruction, that people affected by disasters undertake spontaneously without the involvement of external agencies. (Wisner et al. 2002).

Even though possibilities for community participation may be context and time-specific, the WHO recommends promoting community participation to achieve sustainable development (Wisner et al. 2002).

Community participation includes volunteering, organisational involvement, religious involvement, providing land to the government, and other disaster mitigating organisations (Ali and George 2021; Rayamajhee and Bohara 2021). All these are different examples of how one can invest in community participation. Being a social participant helps for easy resource sharing, faster information dissemination and provides a venue to build trust, interact, and create networks in a community (Abunyewah et al. 2020; Ali and George 2021; Putnam 1995a, b; Rayamajhee et al. 2021; Rayamajhee and Bohara 2021). Evidencebased research from Charleston, North Carolina, shows that those with substantial social influence/involvement were more likely to be evacuated faster than those with weaker social involvement (Riad et al. 1999). Similarly, members in a social event/organisation receive increased and faster support following a disaster event (Nakagawa and Shaw 2004; Rayamajhee et al. 2021).

Research has also linked participation in community activities to lower risky health issues (Hyyppa 2003). Similarly, studies show that social participation allows formulating a necessary public health framework for improving disaster mitigation leading to fewer casualties (Carden 2010; Dynes 2006; Koh and Cadigan 2008; Mathbor 2007; Pelling 1998).

A myriad of research and case studies have proven community participation to be a key element in mitigating disasters. But studies on what drives societies to enhance community participation, its dependencies on socio-economic factors, and whether community 


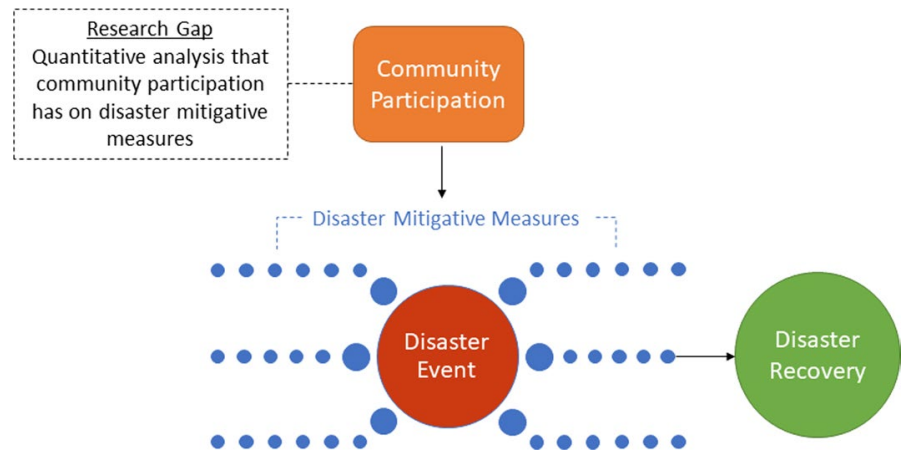

Fig. 1 Research gap in the disaster mitigation domain

participation enhances other disaster mitigation variables are absent. Further, quantitative analysis that community participation has on disaster mitigation measures is scant. In response, this study focuses on quantitatively analysing the relationship between community participation and other disaster mitigation variables through a multivariate probit model (Fig. 1). Pair-wise correlation between variables is also explored to determine if community resilience is distinct and to what extent quantitatively (if it is significant). In addition, socio-economic analysis and conditional probability on community participation and disaster mitigation measures are also explored. This will help disaster authorities and policymakers to implement policies that focus on enhancing community participation more specifically.

Thus, this study is conducted using a live case study in Kochi, India. Residents of Kochi had experienced floods in both 2018 and 2019. The paper is divided into eight sections. The introduction is followed by the literature on disaster mitigation variables and a brief about the Kochi floods. The third section contains the study methodology followed by an empirical model. Finally, the study concludes with a discussion section, study limitations, and conclusion.

\section{Literature review}

\subsection{Determinants of disaster mitigation variables}

Earlier studies have shown that disaster risk reduction measures vary greatly with personal characteristics and situations. Socio-economic factors such as age, gender, household size, income, education, and marital status are reported to be associated with disaster risk reduction measures (Dooley et al. 1992; Heller et al. 2005; Lindell and Whitney 2000; Mitchell 1988; Mulilis et al. 2000; Russell et al. 1995). Besides socio-economic factors, previous experience from similar events encourages a better preparation for disasters than factual knowledge. This experience is directly proportional to the number of disasters encountered (Russell et al. 1995), whether family losses were incurred from a disaster (O'Brien and Mileti 1992), and how recent the tragedy had occurred (Witvorapong et al. 2015).

Community participation is another closely linked disaster risk reduction measure. The strength of community participation comes into foresight, especially in disaster (Dynes 
2002). Before a disaster event, social obligations may be modest. However, people may feel closer to one another in a disaster since they share the same feelings and experiences. The advantages of cooperation are realised, and a sense of belonging is generated during such times (Dynes 2002). This sense of social bonding is even more evident in places exposed to frequent disaster events; this induces the community to share preparedness measures through collective learning (Yamamura 2010). Such times reinforce community participation and social trust (Ali and George 2021; Witvorapong et al. 2015; Yamamura 2010, 2014). Beyond the capacity to support each other, studies have also shown community participation as a contrivance to ameliorate the agony and sufferings of the marginalised population during such times (Abunyewah et al. 2020; Aldrich 2010b, c; Aldrich and Crook 2007; Carden 2010; Rayamajhee and Bohara 2021; 2013a, b). The inability of the elderly, women, children, and other marginalised communities to access aid easily as the non-marginalised community could be addressed by promoting social participation (Aldrich 2010a, 2011b, 2011cAldrich and Crook 2007; Askari et al. 2016; Pourrostami et al. 2020; Reininger et al. 2013a, b).

At times of calamities, knowing the exact ground situation is vital for both the affected and the rescue operators. For this, information sharing and access to such platforms are crucial. The need to closely follow disaster-related news is an essential disaster mitigative measure that would help implement appropriate actions during a disaster (Witvorapong et al. 2015). Resource sharing on social media platforms has also paved the way for faster information dissemination amongst those affected and the officials (Abunyewah et al. 2020; Liu et al. 2021; Ranjit et al. 2020).

Disaster preparedness, prevention, and recovery have been associated with more outstanding social participation, such as perception of trust, positive and closely knit neighbourhood relationships, and involvement in social organisations (Aldrich 2011b; Reininger et al. 2013a, b). However, these studies do not consider social participation to be jointly influenced by the above-said factors. Very few studies, such as (Witvorapong et al. 2015), have studied its combined effects in tsunami-prone areas and found that multiple factors influence social participation and increase with a combination of disaster risk reduction behaviours. This study focuses on this aspect where community participation influences different disaster risk reduction behaviours both combined and individually in flood-prone areas. The study uses a survey of 750 households located in Kochi, India, after the city had experienced ravaging floods in 2018 and 2019, disrupting transport systems and displacing thousands of families. First, a description of the study area is discussed, after which a multivariate probit model is conducted. Finally, the results are discussed.

\subsection{Kochi floods}

Kerala is a South Indian state with more than 33 million population, with a geographic area extending to $39,000 \mathrm{~km}^{2}$. It has a coast of $590 \mathrm{~km}$, and the width of the state varies between 11 and $121 \mathrm{~km}$. Kerala can be divided into three climatically distinct regions: the eastern highlands; rugged and cool mountainous terrain, the central mid-lands; rolling hills, and the western lowlands; coastal plains (Chattopadhyay and Franke 2006). About $90 \%$ of the rainfall in a year occurs during six monsoon months, from June to November. Kerala state has an average annual precipitation of about $3000 \mathrm{~mm}$ (Ministry of Earth Sciences 2019). The continuous and heavy rainfall in the steep and undulating terrain finds its way into the main rivers through innumerable streams and watercourses. Kerala, being a coastal city with a coastline of $590 \mathrm{~km}$, is vulnerable to natural disasters such as floods, tsunamis, and 
even landslides along the slopes of the Western Ghats. There are 39 hazards categorised as naturally triggered hazards and anthropogenically triggered hazards by the Kerala State Disaster Management Plan (The World Bank 2018). Also, Kerala is one of India's most densely populated states with 860 persons per sq. $\mathrm{km}$., making it more susceptible to losses and damages from a disaster (Ministry of Earth Sciences 2019).

Out of all the disasters, floods are the most common disaster in Kerala. Close to 14.5\% area of the state is prone to floods (Ministry of Earth Sciences, 2019). Riverine flooding is a recurring event due to heavy or continuous rainfall. It leads to exceeding the percolation capacity of soil and the flow capacity of streams and rivers. The events that trigger an inundation are mainly rainfall, channel slope, land use in the flood plains, materials of stream banks, and relative height of banks (Ministry of Earth Sciences, 2019).

Before the flood of 2018 and 2019, the previous flood of such a devastating scale happened in 1924, almost a century ago. More commonly known as the ' 99 floods, since it happened in the Malayalam calendar year of 1099, the then flood had deeply submerged many districts of Kerala from Thrissur to Alappuzha, even parts of Idukki. After 1924, the next major flood was in 1961 in the Kerala Periyar Basin, with a 52\% increase in Monsoon rains. However, casualties were relatively lesser, at 110 , than the previous event due to lesser urban densities in these areas.

The flood seems to be recurring at a closer frequency, especially when it is happening back-to-back years. The year 2019 ran through a deficit of 29\% rainfall on 1 August 2019 to no shortage on 14 August 2019, implying the excess rain was received in just two short weeks (Ministry of Earth Sciences 2019). Houses damaged due to flooding stood at 1789, and over 26,000 people have taken refuge in relief camps (Ministry of Earth Sciences, 2019). Out of all the districts in Kerala, Kochi seems to be the most affected in infrastructure, transportation, and economic terms.

The area was severely affected during the floods of 2018 and 2019, disrupting roadways, railways, and even airways. All transportation networks were submerged in water for at least two weeks during the 2018 flood. The central location of Kochi for the state of Kerala resulted in separating the state into two parts. All state functioning and even rescue operations were severely affected. Rescue operations during these times were mainly through local boats used by fishermen residing in the area (Ali and George 2021).

\section{Methodology}

\subsection{Quantitative analysis}

This study analyses community participation's impact on disaster mitigation measures following the Kochi flood of 2018 and 2019 in India. For this, we have used a multivariate probit regression model with a sample size of 750 to analyse the relationship between disaster mitigation measures, namely disaster event planning, previous experience, following disaster-related updates, neighbourhood relationship, and community participation.

The study is analysed in three parts. First, a multivariate probit regression model is conducted to examine the significance between socio-economic factors and disaster mitigation variables. Here, all variables including 'community participation' are considered as a dependent variable. Second, correlation between all the disaster mitigation variables is analysed. Again, all variables are considered as dependent variables, including 'community participation'. Third, a conditional probability between 'community participation' and 
other disaster mitigation measures is analysed. Here, 'community participation' is considered an independent variable while all other variables are dependent variables.

\subsection{Site and sampling}

The site selected for the study is Kochi Municipal Corporation limits in Kerala. We followed the systemic random sampling method. Every third household was surveyed within the 74 wards of the municipal corporation area (Fig. 2 shows the ward distribution in the Kochi municipal corporation area.) The population of the Kochi municipal corporation is 677,381 (Bose 2011). The study used a confidence interval of $95 \%$ with a $5 \%$ margin of error using Cochran's (1977) formula for calculating sample size. The survey count does not vary significantly for a vast population, and hence, the minimum required sample size is 385 responses. The surveyed sample size stands at 750 surveys and is higher than the minimum requirement. A door-to-door survey was conducted in all the 74 wards, ensuring at least ten households were surveyed in each ward.

\subsection{Safety precautions}

The survey was conducted during February-March 2021, which was during the corona-virus pandemic. However, since the government of India had removed the country's lockdown by this time, we were able to conduct the survey. All safety protocols were followed, including double face masks, hand gloves, social distancing, and frequent use of sanitisers. Households had the absolute right to decline the survey without stating any reason, resulting in a response rate of $78 \%$ in household participation. Figures 3 and 4 show the current scenario of the areas submerged in water during the 2018 flood, which was also the study area.

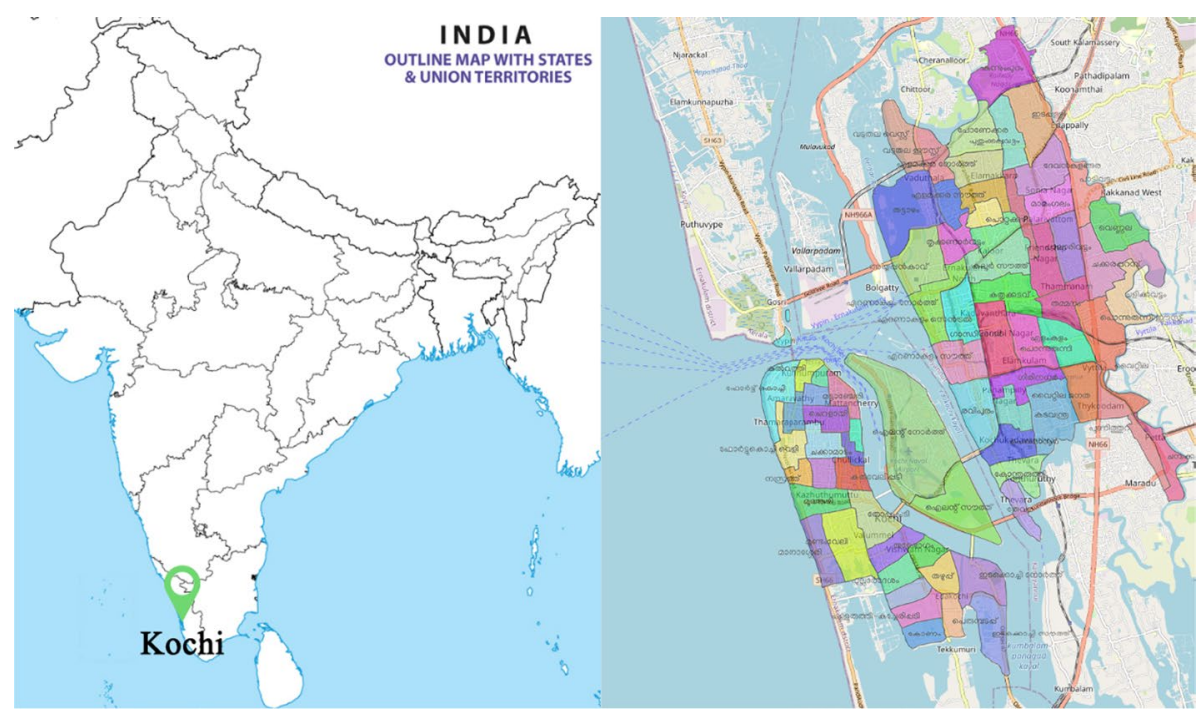

Fig. 2 Kochi Municipal Corporation Map, Source: (Open Street Map) 


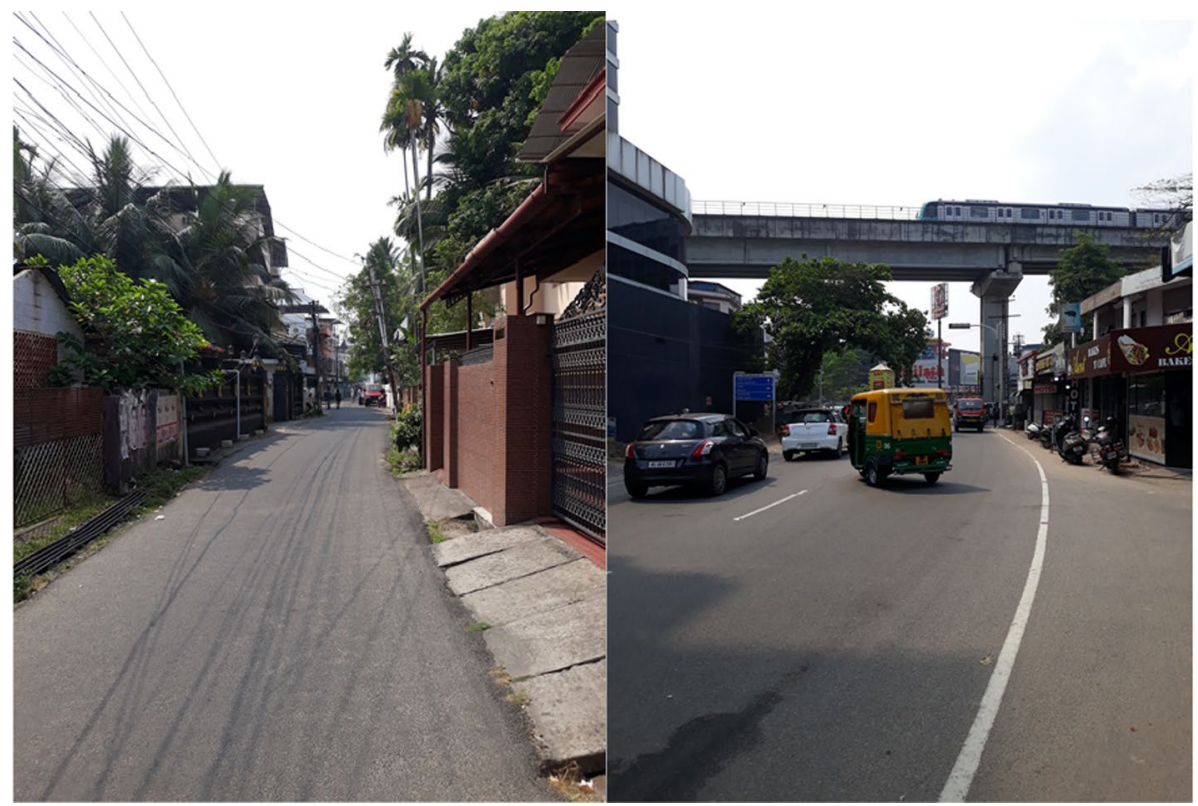

Fig. 3 Site Photographs, Location: Kochi

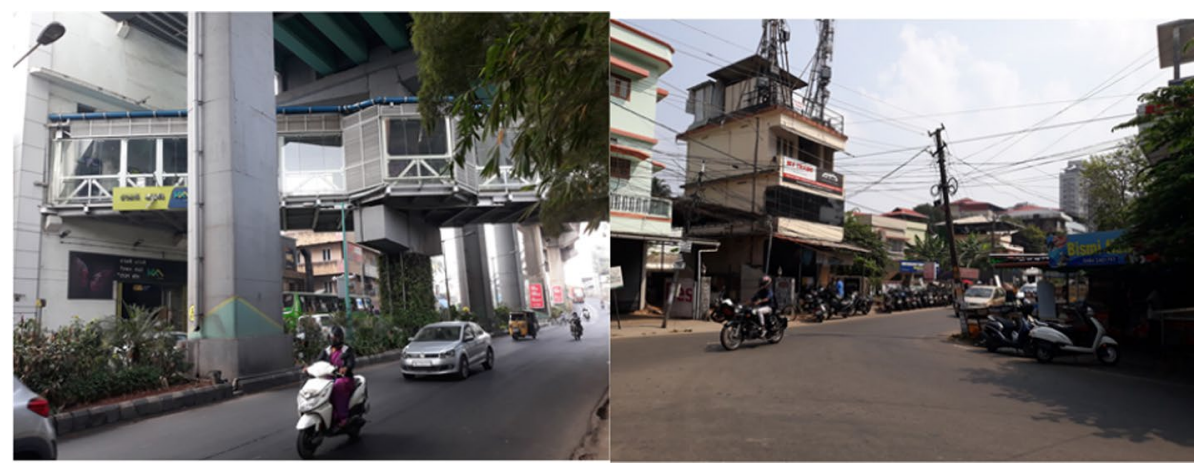

Fig. 4 Site Photographs 2, Location: Kochi

\subsection{Survey questionnaire}

A 20-item in-person survey was conducted. The questionnaire was divided into two parts. The first part included socio-economic characteristics such as age group, gender, household size, household income, education level, and the presence of a special needs person (SNP). The second part included disaster mitigation variables such as community participation, disaster event planning, previous experience of a disaster, following disaster-related news closely, and neighbourhood relationship. The questions related to disaster mitigation were developed from earlier assessments of Witvorapong et al. (2015) and Aldrich (2011a, b,c). Even though the questionnaire was in English, 
Table 1 Descriptive statistics

\begin{tabular}{lcc}
\hline Variable & Frequency & Percentage \\
\hline Gender & & \\
Male & 395 & 52.67 \\
Female & 355 & 47.33 \\
Age group & & \\
18-24 & 136 & 18.13 \\
$25-34$ & 189 & 25.20 \\
$35-44$ & 200 & 26.67 \\
$45-54$ & 196 & 26.13 \\
$55+$ & 29 & 3.87 \\
Household size & & \\
1 & 97 & 12.93 \\
2 & 99 & 13.20 \\
3 & 326 & 43.47 \\
4 & 162 & 21.60 \\
5-6 & 59 & 7.87 \\
$7+$ & 7 & 0.93 \\
Education level & & \\
Illiterate & 7 & 0.93 \\
Primary school & 14 & 1.87 \\
High school & 142 & 18.93 \\
Graduate & 369 & 49.20 \\
Post-graduate & 218 & 29.07 \\
Differently abled persons & 111 & 14.80 \\
Married & 473 & 63.07 \\
\hline
\end{tabular}

questions were asked in the local language, namely Malayalam, since the survey was conducted verbally.

After collecting all the surveys (750), statistical analysis using multivariate probit regression (MVPR) for five disaster mitigation variables was analysed with socio-economic factors. We conducted the research using Stata13 software. Descriptive statistics of the study are shown in Table 1. The empirical model followed and formulas used to conduct MVPR are explained. First, the results on significance are discussed, including positive and negative coefficient values, after which correlation between variables has also been analysed. Further, conditional probability for 'community participation' has been conducted.

\section{Description of variables}

\subsection{Socio-economic variables}

The study considered six socio-economic items. The initial question included selecting their gender from male, female, transgender, and an option not to specify. Age group was measured by a close-ended question that consisted of the following response categories (18-24, 25-34, 35-44, 45-54, 55+). Monthly income was measured with the following response categories ( $<$ Rs.30000, $<$ Rs.50000, $<$ Rs.75000, $<$ Rs.100000, $\geq$ Rs.100000). 
After which, respondents were asked if they were married or unmarried. Those who responded as divorced or widowed were also considered under the category of unmarried. Education was measured in five levels: no formal education, primary school, high school, graduate, and post-graduate. Households with a special needs person (SNP) were assessed based on questions related to the presence of a differently abled person, a person with mental or physical disabilities and dependence for routine care or require medical assistance and medication. Household sizes were measured in five levels: single occupancy, double, $3-4,5-6$, and 7 or above. After the socio-economic section, participants were asked questions related to disaster mitigation and their awareness.

\subsection{Measurement of disaster mitigation variables}

Five disaster mitigation variables were analysed for the task. The question that measured community participation was 'Are you active in any Social/Community Events/Awareness Events?'. In addition, participants were asked which events they participate in and their frequency of attendance. Community events were not always a physical event. Many of the events are held virtually through video conferences/phone calls/WhatsApp messages. However, if the respondent was active in any of the social events through any means such that their involvement was present, the respondent was considered an active participant. Else, the respondent was marked as inactive.

Respondents were then asked if they had good contacts with their immediate neighbours. Responses such as 'not in talking terms' were perceived as a 'No'. After which, questions related to flood-related experiences were asked. 'Following Disaster-related updates' was asked as 'Had you closely followed flood-related updates on any media (Smartphone/T.V./Laptop/Radio)?', this is to make sure respondents were aware of the situation around. Next, the factor 'Disaster event planning' was asked as 'Had you prepared Emergency kits or had an emergency evacuation plan?'. Such measures are a critical disaster mitigation factor for any disaster (Bell et al. 2020; Lam et al. 2017; McNeill et al. 2018; Pickering et al. 2018; Wilkinson et al. 2018). The next question enquired about the knowledge gained from a similar experience if applicable. Respondents were asked if they had experienced any disaster previously and if it helped them in any way during the 2018/2019 floods. Most respondents had an experience of the 2018 flood. Hence, some respondents were better prepared for the 2019 flood from the experience of the previous year.

\section{Empirical estimation}

\subsection{Empirical model}

The following section explains all the formulas used to conduct the study. Latent variable $\left(Y_{i k}^{*}\right)$ determined by observed explanatory variable $\left(X_{i}\right)$ and the error term $\left(\varepsilon_{i}\right)$ is defined as ( $\beta$ represents the vector of coefficients to be estimated):

$$
Y_{i k}^{*}=X_{i}^{\prime} \beta_{k}+\varepsilon_{k i} \text { where, }(k=Y 1+Y 2+Y 3+Y 4+Y 5)
$$

where $Y_{i k}=\left\{\begin{array}{ll}1 & \text { if } Y_{i k}^{*}>0 \\ 0 & \text { Otherwise }\end{array}\left(k=Y_{1}, Y_{2}, Y_{3}, Y_{4}, Y_{5}\right)\right.$ 
From the above equations, the following latent variable models are assumed:

1. $C_{i}^{*}=X_{i}^{\prime} \beta_{C}+\varepsilon_{C i}$ (where $C$ represents community participation)

2. $D_{i}^{*}=X_{i}^{\prime} \beta_{D}+\varepsilon_{D i}$ (where $\mathrm{D}$ represents disaster event planning)

3. $P_{i}^{*}=X_{i}^{\prime} \beta_{P}+\varepsilon_{P i}$ (where $\mathrm{P}$ represents previous experience)

4. $F_{i}^{*}=X_{i}^{\prime} \beta_{F}+\varepsilon_{F i}$ (where $\mathrm{F}$ represents following disaster-related updates)

5. $N_{i}^{*}=X_{i}^{\prime} \beta_{N}+\varepsilon_{N i}$ (where $\mathrm{N}$ represents neighbourhood relationship)

The multivariate probit model assumes the error terms (five) are correlated according to a multivariate normal distribution as follows:

$$
\left[\begin{array}{c}
\varepsilon_{\mathrm{Ci}} \\
\varepsilon_{\mathrm{Di}} \\
\varepsilon_{\mathrm{Pi}} \\
\varepsilon_{\mathrm{Fi}} \\
\varepsilon_{\mathrm{Ni}}
\end{array}\right] \sim N\left[\left[\begin{array}{l}
0 \\
0 \\
0 \\
0 \\
0
\end{array}\right]\left[\begin{array}{ccccc}
1 & \rho_{\mathrm{CD}} & \rho_{\mathrm{CP}} & \rho_{\mathrm{CF}} & \rho_{\mathrm{CN}} \\
\rho_{\mathrm{CD}} & 1 & \rho_{\mathrm{DP}} & \rho_{\mathrm{DF}} & \rho_{\mathrm{DN}} \\
\rho_{\mathrm{CP}} & \rho_{\mathrm{DP}} & 1 & \rho_{\mathrm{PF}} & \rho_{\mathrm{PN}} \\
\rho_{\mathrm{CF}} & \rho_{\mathrm{DF}} & \rho_{\mathrm{PF}} & 1 & \rho_{\mathrm{FN}} \\
\rho_{\mathrm{CN}} & \rho_{\mathrm{DN}} & \rho_{\mathrm{PN}} & \rho_{\mathrm{FN}} & 1
\end{array}\right]\right]=\operatorname{Normal}(0, \Omega)
$$

where $N=$ normal distribution, $0=$ expected error term value, $\Omega=$ variance-covariance matrix of the error terms (Symmetric), $\rho=$ conditional tetrachoric correlation for each pair of outcomes.

\subsubsection{Cumulative probability distribution function}

$$
\begin{aligned}
\operatorname{Pr} & \left.C_{i}=1, D_{i}=1, P_{i}=1, F_{i}=1, N_{i}=1\right) \\
& =\int_{-\infty}^{\varepsilon_{C i}} \int_{-\infty}^{\varepsilon_{D i}} \int_{-\infty}^{\varepsilon_{P i}} \int_{-\infty}^{\varepsilon_{F_{i}}} \int_{-\infty}^{\varepsilon_{N i}} \Phi_{5}\left(X_{i}^{\prime} \beta_{C}, X_{i}^{\prime} \beta_{D}, X_{i}^{\prime} \beta_{P}, X_{i}^{\prime} \beta_{F}, X_{i}^{\prime} \beta_{N} ; \rho_{\mathrm{CD}}, \rho_{\mathrm{CP}}, \rho_{\mathrm{CF}}, \rho_{\mathrm{CN}}, \rho_{\mathrm{DP}}, \rho_{\mathrm{DF}}, \rho_{\mathrm{DN}}, \rho_{\mathrm{PF}}, \rho_{\mathrm{PN}}, \rho_{\mathrm{FN}}\right) \mathrm{d} \varepsilon_{\mathrm{Ci}} \mathrm{d} \varepsilon_{\mathrm{Di}} \mathrm{d} \varepsilon_{\mathrm{Pi}} \mathrm{d} \varepsilon_{\mathrm{Fi}} \mathrm{d} \varepsilon_{\mathrm{Ni}} \\
= & \Phi_{5}\left(X_{i}^{\prime} \beta_{C}, X_{i}^{\prime} \beta_{D}, X_{i}^{\prime} \beta_{P}, X_{i}^{\prime} \beta_{F}, X_{i}^{\prime} \beta_{N} ; \rho_{\mathrm{CD}}, \rho_{\mathrm{CP}}, \rho_{\mathrm{CF}}, \rho_{\mathrm{CN}}, \rho_{\mathrm{DP}}, \rho_{\mathrm{DF}}, \rho_{\mathrm{DN}}, \rho_{\mathrm{PF}}, \rho_{\mathrm{PN}}, \rho_{\mathrm{FN}}\right)
\end{aligned}
$$

where $\Phi_{5}=$ Joint probability density function of the fifth order.

\subsubsection{Log-Likelihood function}

$$
\begin{aligned}
\ln L & =\sum_{i=1}^{N} C_{i}^{*} * D_{i}^{*} * P_{i}^{*} * F_{i}^{*} * N_{i}^{*} \\
& * \ln \Phi_{5}\left(X_{i}^{\prime} \beta_{C}, X_{i}^{\prime} \beta_{D}, X_{i}^{\prime} \beta_{P}, X_{i}^{\prime} \beta_{F}, X_{i}^{\prime} \beta_{N} ; \rho_{C D}, \rho_{C P}, \rho_{C F}, \rho_{C N}, \rho_{D P}, \rho_{D F}, \rho_{D N}, \rho_{P F}, \rho_{P N}, \rho_{F N}\right)
\end{aligned}
$$

Since the number of integrals is more than two (five in this case), the traditional maximum likelihood method may be computationally burdensome. Hence the simulated maximum likelihood (SML) method based on the Geweke-Hajivassiliou-Keane recursive simulator is used. The minimum number of draws required for conducting should be greater than the square root of the total number of observations taken into consideration, the square root of $750=28$. The study has used 30 draws. Stata (version 13) has been used for conducting multivariate probit regression of the above research. Table 2 shows the descriptive statistics of the combination of probit variables considered. 


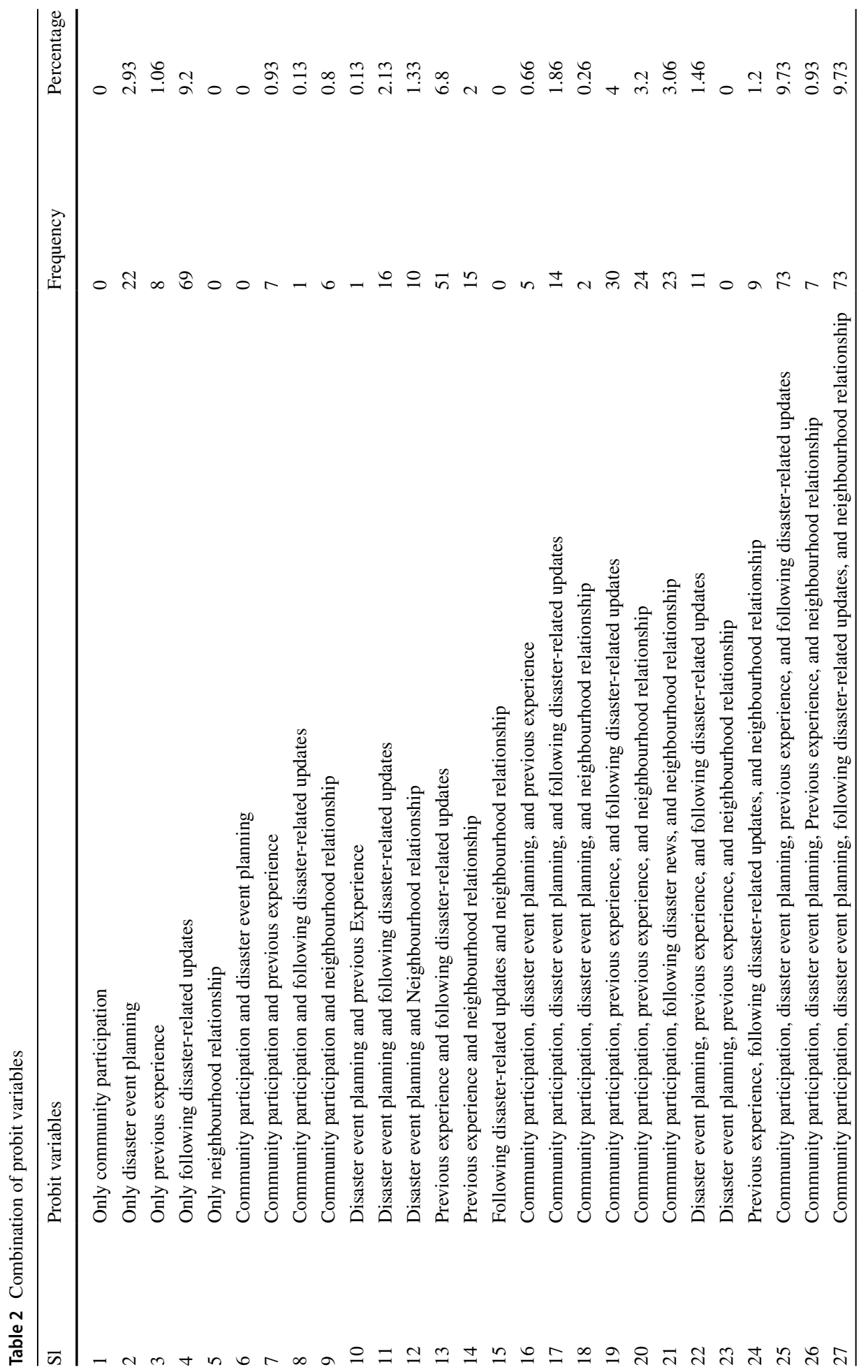









\subsection{Results}

A multivariate probit regression for all the disaster mitigation measures was analysed. From Table 3, it is clear that all five selected variables have statistical significance with regard to socio-economic factors. A negative and significant coefficient of age groups reflects that community participation decreases with higher age group, i.e. people within lower age groups seem to be more active participants in social events. A positive and significant coefficient of education level and households with special needs persons shows that community participation increases with an increase in education level and is also prominent with families with differently abled people.

In disaster event planning, 'coefficients of age group', 'households with special needs persons', 'higher education level', and 'married households' have positive coefficients, which means disaster event planning is directly proportional to these factors. Negative and significant value for married homes and those with previous experience of a similar event shows that unmarried households are more likely to be better prepared for a disaster if they have had experience from a similar event previously.

Females tend to be more active in following disaster-related updates as compared to male counterparts. Positive coefficients for households with special needs persons also imply that such families are more likely to follow disaster-related updates. Negative and significant coefficients for age group in neighbourhood relationship shows that, if all other

Table 3 Multivariate probit model analysis

\begin{tabular}{llllll}
\hline Variable & $\begin{array}{l}\text { Community } \\
\text { participation }\end{array}$ & $\begin{array}{l}\text { Disaster } \\
\text { event plan- } \\
\text { ning }\end{array}$ & Previous experience & $\begin{array}{l}\text { Following } \\
\text { disaster-related } \\
\text { updates }\end{array}$ & $\begin{array}{l}\text { Neigh- } \\
\text { bourhood } \\
\text { relationship }\end{array}$ \\
\hline Gender & 0.107 & -0.148 & -0.065 & $0.387^{* *}$ & 0.134 \\
& $(0.967)$ & $(0.099)$ & $(0.098)$ & $(0.113)$ & $(0.090)$ \\
Age group & $-0.096^{*}$ & $0.140^{* *}$ & -0.045 & -0.040 & $-0.101^{*}$ \\
Household size & $(0.041)$ & $(0.045)$ & $(0.043)$ & $(0.050)$ & $(0.039)$ \\
& 0.095 & 0.087 & -0.012 & -0.118 & -0.005 \\
Special needs person & $(0.056)$ & $(0.056)$ & $(0.057)$ & $(0.065)$ & $(0.052)$ \\
(SNP) & $0.294^{*}$ & $1.115^{* *}$ & 0.228 & $0.757^{* *}$ & -0.194 \\
Education level & $(0.148)$ & $(0.163)$ & $(0.156)$ & $(0.214)$ & $(0.138)$ \\
& $0.163 *$ & $0.426^{* *}$ & 0.085 & 0.027 & $0.131^{*}$ \\
Married & $(0.067)$ & $(0.064)$ & $(0.062)$ & $(0.067)$ & $(0.057)$ \\
& 0.051 & $0.531^{* *}$ & $-0.280^{*}$ & 0.197 & $0.348^{* *}$ \\
Constant & $(0.128)$ & $(0.129)$ & $(0.135)$ & $(0.143)$ & $(0.120)$ \\
Log-likelihood=-1773.978 & -0.286 & 0.459 & $0.641^{*}$ & $0.968^{* *}$ & $0.725^{*}$ \\
Number of observations $=750$ & $(0.350)$ & $(0.334)$ & $(0.318)$ & $(0.359)$ & $(0.299)$ \\
Draws =30 & & & & & \\
Wald Chi. Sq. $(30)=257.10$ & & & & & \\
Prob. $>$ Chi. Sq. =0.00 & & & & & \\
\hline
\end{tabular}

Standard errors are in parenthesis. Likelihood ratio test of rho $21=\operatorname{rho} 31=\operatorname{rho} 41=\operatorname{rho} 51=\operatorname{rho} 32=\operatorname{rho} 42=$ rho52 $=\operatorname{rho} 43=\operatorname{rho53}=\operatorname{rho} 45=0 \operatorname{chi} 2(10)=662.924, \operatorname{Prob}>\operatorname{chi} 2=0.0000$

$* p<0.05, * * p<0.01$ 
values remain the same, higher aged people are less likely to mingle and bond with their neighbours. On the other hand, positive coefficients for education level and married people imply that people with higher education levels and those married have a higher chance of knowing and having positive ties with their neighbours.

\subsection{Correlation between variables}

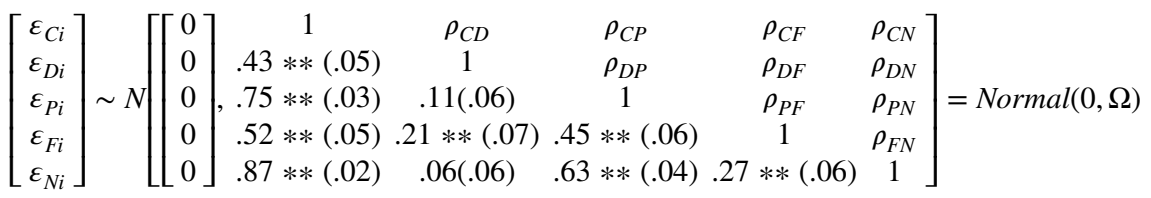

Note: $* * p<0.01$

Pair-wise correlation coefficients are studied using multivariate probit regression to help understand the correlation between the selected variables. From the correlation matrix, it is clear that most of the pair-wise correlation coefficient is significant, with the highest correlation between 'community participation' and 'neighbourhood relationship' with $\rho_{C N}$ value of 0.87 , which is followed by 'community participation' and 'previous experience' with $\rho_{C P}$ value of 0.75 . The significance between variables justifies using a multivariate probit model instead of an independent probit model.

\subsection{Conditional probability}

Very high significance exists between 'community participation' and all other variables. Conditional probability between all variables and "community participation is studied to understand this significance. Drawing on the predicted joint probabilities as explained earlier, the paired difference of conditional probability values when 'community participation' is present and absent are charted (Table 4).

Table 4 Conditional probability on community participation

\begin{tabular}{|c|c|c|c|c|}
\hline Events & $\begin{array}{l}\text { When commu- } \\
\text { nity participa- } \\
\text { tion }=1\end{array}$ & $\begin{array}{l}\text { When commu- } \\
\text { nity participa- } \\
\text { tion }=0\end{array}$ & Paired difference & $t$ test statistics \\
\hline Disaster event planning $=1$ & 0.46 & 0.08 & 0.38 & $191.22 * * *$ \\
\hline Previous experience $=1$ & 0.64 & 0.12 & 0.52 & $258.96 * * *$ \\
\hline $\begin{array}{l}\text { Following disaster-related } \\
\quad \text { updates }=1\end{array}$ & 0.73 & 0.30 & 0.43 & $201.28 * * *$ \\
\hline Neighbourhood relationship $=1$ & 0.62 & 0.04 & 0.58 & $276.34 * * *$ \\
\hline $\begin{array}{l}\text { Disaster event planning }=0 \text {, pre- } \\
\text { vious experience }=0, \text { following } \\
\text { disaster-related updates }=0, \\
\text { neighbourhood relationship }=0\end{array}$ & 0.00 & 0.02 & -0.02 & $-43.50^{* * * *}$ \\
\hline $\begin{array}{l}\text { Disaster event planning }=1 \text {, pre- } \\
\text { vious experience }=1 \text {, following } \\
\text { Disaster-related updates }=1 \text {, } \\
\text { neighbourhood relationship }=1\end{array}$ & 0.23 & 0.00 & 0.23 & $147.45 * * *$ \\
\hline
\end{tabular}

$* * *$ Significant at $p<0.001$ 
The first four rows show the conditional probability of each disaster mitigation measure independently with community participation using the bivariate probit model. This is done to study the relationship between each disaster mitigation measure to understand their separate impacts on 'community participation' irrespective of others. The remaining two rows explain conditional probability when all events co-occur using the multivariate probit model. The first two columns define the probabilities when people have some to no community participation and are active community participants. The third column illustrates the paired difference of the before mentioned probabilities, and the final column shows the significance using the t-test statistics.

The conditional probability of the above variables shows that community participation influences the other variables positively. Without the presence of 'community participation', the rate of 'disaster event planning', 'previous experience,' 'following disaster-related updates', and 'neighbourhood relationship' stands at 8, 12, 30, and 4\%, respectively. But the same increases by $38,52,43$, and $58 \%$ with community participation. A negative paired difference in the fourth row shows no such event, implying that, following all other disaster mitigation measures without community participation, does not cease to exist. Simultaneously, the paired difference increases by $23 \%$ for all other disaster mitigation measures with community participation.

\section{Discussion}

The paper examines the relationship between community participation and disaster mitigation measures using a case study of disaster mitigation response during the Kochi flood of 2018 and 2019 in Kerala, India. We investigate five disaster mitigation behaviours: disaster event planning, experience from previous similar events, following disaster-related updates closely, neighbourhood relationships, and community participation. The study analysed socio-economic significance, modelled the probability of engaging in community events, and quantified the relationship between community participation and disaster mitigation behaviours by estimating conditional probabilities.

\subsection{Study findings}

The significant finding from this study is that community participation is highly correlated to disaster mitigating variables. The probability of undergoing disaster event planning, following disaster-related updates, learning from previous experiences to be better prepared for the future, and having a neighbourhood relationship increases significantly for those involved in community activities. As evident from the previous literature, community participation helps share resources and expertise, facilitates easy transmission of critical information, provides a venue to build trust, interact, and creates networks in a community that would eventually benefit individuals during times of distress (Ali and George 2021; Crabbé and Robin 2006; Ford et al. 2006; Tompkins 2005). Community participation also brings out positive externalities such as surviving in old age and increasing leisure-time physical activity (Lindström et al. 2001; Maier and Klumb 2005). These factors suggest that community participation can be beneficial for disaster mitigation.

Studies have shown that first responders are usually family, neighbours, and friends (Ali and George 2021; Perrow 2007). Such has been the case in this study as well. Most responders said they benefited immensely from their neighbours' support, including 
physical and mental aid. Studies have shown that individuals sometimes rely on other households and people living close by to evacuate them (Reininger et al. 2013a, b). Policymakers could develop intervention models, such as using community heads or neighbourhood leaders to disseminate critical information and foster greater participation amongst families and neighbours to prepare for a disaster (Reininger et al. 2013a, b).

Having a previous experience of a similar event did not necessarily increase disaster preparedness. It was only prevalent amongst households with a special needs person or people with higher education levels. When asked to the responders why efforts were not taken to prepare emergency kits even after experiencing floods back-to-back years, people did not expect life-altering events to happen frequently, was the response. This is in line with many studies that claim having a previous experience of a similar condition may not increase disaster preparedness (Kohn et al. 2012; Witvorapong et al. 2015). Respondents linked it to wastage of resources and space, and such measures were primarily overseen by the economically weaker section of the society.

Different disaster mitigating measures require varying levels of effort (Witvorapong et al. 2015). For example, following disaster-related news only requires a smartphone connection. But preparing an emergency kit or setting out an escape plan requires more time and effort. Our study shows that the latter measures of having an emergency kit ready were more prominent with graduates or above. The above factors show the importance of education levels (Teo et al. 2018). Governments will have to invest in these sectors, which in turn may affect disaster mitigation efforts positively. However, this is not true for places that experience disasters frequently. For example, research has shown that $59 \%$ of the economically weaker section of the society had prepared emergency kits in Texas, USA, as their city was prone to frequent hurricanes (Reininger et al. 2013a, b).

Mixed evidence exists in the case of people with special needs and disaster preparedness. Studies from the USA have shown no significance between households with a special needs person (SNP) and disaster preparedness (Bethel et al. 2011; Eisenman et al. 2009; Uscher-Pines et al. 2009). However, our study lies in line with Witvorapong et al. (2015) results, where households with a special needs person did indeed increase the likelihood of having disaster kits prepared.

Regarding disaster mitigation differences amongst gender, women tend to be more prepared than men, which could be since women tend to perceive disaster or threats much more seriously than men (Cutter et al. 1992; Fothergill 1996; Witvorapong et al. 2015). Also, certain studies explain that disaster impacts affect women more than men (Hamidazada et al. 2019; Nguyen 2018; Tanyag 2018; Teo et al. 2018). Consequences range from lower opportunities to learn about disaster mitigation measures to women exploitation post-disaster (Fujii \& Kanbara 2019; Hamidazada et al. 2019). Furthermore, research has linked female education to play a vital role in lowering health risks in children, reducing disaster-related mortality counts, and enhancing adaptive capacity (Ostad-Ali-Askari et al. 2020; Siri 2014; Striessnig et al. 2013; Talebmorad et al. 2021; Wamsler et al. 2012). Since women are more likely to have a more robust social connection with neighbours than men (Renzulli et al. 2000; Witvorapong et al. 2015), providing education opportunities for women could improve disaster mitigation measures in a community.

In 2013, under the Ministry of Law and Justice, India, 'The National Food Security Act,2013' was passed by the parliament. It declared women the head of the family in issuing a 'ration card' (Ministry of Law and Justice 2013). The government of India passed an act to provide subsidised food grains, especially for the economically weaker sections. The rationale for making women the head of the family was because the government believed women were better homemakers than men (Lakkadi 2013). The takeaway here is that 
women seem to be better at the job than men regarding household sustainability. Disaster mitigation measures could very well fall on the same line if women are empowered with education and opportunities.

This study has also found significance with disaster event planning increasing with higher age groups. People aged more than 55 were common in households with a larger number of people. Some studies have shown that, in specific communities, the elder in the family holds the highest responsibility of its members due to their life experiences and more significant connections with decision-makers (Reininger et al. 2013a, b). But in households with really aged people who need external support due to their physical conditions, they also seem to implement more disaster preparedness measures. (The study has considered such household members under the category of 'special needs person'.)

Another unique observation while conducting the survey saw existing communities followed a multicultural settlement pattern, which included daily wage workers to highly respected doctors and lawyers on the same street lanes. Respondents claimed they were highly benefitted from this mixed household pattern. People in different strata of the society had access and knowledge of various resources which would otherwise be absent for a particular section. For example, daily wage workers had acquaintances with the local fishermen, who passed the information of those stranded and eventually were rescued on local boats. Here, multiple instances of resource sharing are something not to be overlooked. Expansion of community participation depends on encompassing the excluded sections of society (Aldrich 2011b; Elliott et al. 2010).

\subsection{Conditional probability on community participation}

Conditional probability on community participation and other measured disaster mitigation measures showed high significance. The chances of individuals undertaking all other disaster mitigation measures increased by $23 \%$ compared to when community participation was absent. Individuals could be encouraged to participate in community events or volunteer in public programmes. A community 'currency program' implemented by the government of Japan for Ichikawa city to promote social participation resulted in higher trust levels amongst citizens. Here the community currency was earned for volunteering in social events and could be used at local shops (Richey 2007). Taking ideas from such measures could improve community participation leading to increased disaster preparedness by disaster mitigation professionals.

\subsection{Future scope}

Even though numerous studies highlight the relevance of community participation in disaster mitigation (Ada and Bolat 2010; Aldrich 2011a, 2012; Koh and Cadigan 2008; Mathbor 2007), post-disaster aid primarily focuses on physical restoration from the effects of the disaster. Instead, organisations should focus more on community rehabilitation and promote social participation to help individuals be better prepared and thereby decrease mortality rates.

Another aspect of increased community participation could be including the neglected sections of the society to inculcate similar skills (Abunyewah et al. 2020; Aldrich 2011b; Elliott et al. 2010). For example, the Tata Institute of Social Sciences (TISS) has developed and promoted leadership seminars across India to connect and increase the mobilisation capacity of people excluded from the outside communities like the tribal people. 
The 'Kudumbashree' organisation (a joint programme between the National Bank for Agriculture and Rural Development and the Government of India) in Kerala, India, focuses on the upliftment of women, especially the economically weaker section. The programme is aimed to provide economic opportunities to expand their livelihood and thus provide for society (Ali and George 2021). The same 'Kudumbashree' organisation also provided counselling support to more than 10,000 families and helped distribute relief material after the 2018 Kerala flood (Ali and George 2021). Such initiatives are long-term investments that different organisations must ensure in developing, especially when disaster preparedness is considered. Promoting community participation in public events and proposals to interlink social events to strengthen the deprived sections of the society could play a vital role in disaster preparedness from unanticipated future events.

\section{Limitations}

This study has focussed on the effects of community participation solely on a flood-prone area. The results cannot be generalised as they are context-specific and depend on other factors such as the city's age, rate of in and out migrants, and other social and political dependencies. The study also does not consider the strengths and types of community participation individuals undergo, often referred to as bonding and bridging (de Souza Briggs 2004). Other variables of community participation include trust, strong and weak ties of communities in access to resources, and support during times of distress. Instead, the study has focused on the presence and absence of self-reported community participation and its effects on disaster mitigation measures. Future research should consider analysing the types of communities in society, political mindsets, and segregation if applicable, and the strength and involvement of community heads with policymakers. Such measures could further explain the barriers and issues that are hindrances in building and promoting community participation.

Broader networks, such as interlinkage between local community groups and national/ international scale agencies for combined disaster mitigating efforts, can be explored in future research.

\section{Conclusion}

The study conducted here is of a particular case since the city had experienced floods consecutively for two years when the previous experience of a disaster of such scale had happened almost a century ago. People are exposed to unanticipated events as they lack prior experience. However, with the floods occurring in 2018 and 2019, only a portion of the community had prepared beforehand. The primary reason being stated that reoccurring events were unheard of at the location. However, this study reveals that the community's level of social participation had helped them cope with the disaster to a large extent. This study finds that community participation is significant and increases the chances for participants to take up other disaster mitigation measures, thereby reducing the effects of the disaster.

The results show participants who were active in community events were $23 \%$ more likely to adopt all the disaster mitigation measures than those who did not. In addition, households with special needs members were more likely to be prepared for an 
unanticipated event. The results also showed higher education levels directly correlated to implementing more significant disaster mitigation measures. Implications for government policy formation include schemes to enhance community rehabilitation and promote social participation to mitigate future disaster events.

Declaration Partial financial support was received from the Ministry of Education, India.

The authors have received consent from an organising committee of the Department of Architecture and Regional Planning, Indian Institute of Technology Kharagpur, for conducting this study. The authors followed all ethical research considerations, and all COVID-19 protocols were followed as per the Government of India's regulations.

\section{References}

Abunyewah M, Gajendran T, Maund K, Okyere SA (2020) Strengthening the information deficit model for disaster preparedness: mediating and moderating effects of community participation. Int J Disaster Risk Reduct 46:101492. https://doi.org/10.1016/j.ijdrr.2020.101492

Ada S, Bolat Oİ (2010) The importance of social capital in emergency management: a literatüre survey. Balikesir Univ J Soc Sci Inst 13(24)

Aldrich DP (2010a) Fixing recovery: social capital in post-crisis resilience. J Homeland Secur

Aldrich DP (2010b) Separate and unequal: post-tsunami aid distribution in Southern India*. Soc Sci Q 91(5):1369-1389. https://doi.org/10.1111/j.1540-6237.2010.00736.x

Aldrich DP (2010c) The power of people: social capital's role in recovery from the 1995 Kobe earthquake. Nat Hazards 56(3):595-611. https://doi.org/10.1007/s11069-010-9577-7

Aldrich DP (2011a) Social, not physical, infrastructure: the critical role of civil society after the 1923 Tokyo earthquake. Disasters 36(3):398-419. https://doi.org/10.1111/j.1467-7717.2011.01263.x

Aldrich DP (2011b) The externalities of strong social capital: post-tsunami recovery in Southeast India. J Civ Soc 7(1):81-99. https://doi.org/10.1080/17448689.2011.553441

Aldrich DP (2011c) Ties that bond, ties that build: social capital and governments in post disaster recovery. Stud Emergent Order 4:58-68

Aldrich DP (2012) Building resilience: social capital in post disaster recovery. University of Chicago Press. https://doi.org/10.7208/chicago/9780226012896.001.0001

Aldrich DP, Crook K (2007) Strong civil society as a double-edged sword. Polit Res Q 61(3):379-389. https://doi.org/10.1177/1065912907312983

Ali S, George A (2021) Social inclusivity: a case study on Community Resilience on Kerala Flood-2018. In: Lecture notes in civil engineering. Springer, Singapore, pp 109-131. https://doi.org/10.1007/ 978-981-15-9585-1_8

Askari G, Heidari-Beni M, Mansourian M, Esmaeil-Motlagh M, Kelishadi R (2016) Interaction of lipoprotein lipase polymorphisms with body mass index and birth weight to modulate lipid profiles in children and adolescents: the CASPIAN-III Study. Sao Paulo Med J 134(2):121-129. https://doi.org/10.1590/ 1516-3180.2015.00792608

Bell SA, Singer D, Solway E, Kirch M, Kullgren J, Malani P (2020) Predictors of emergency preparedness among older adults in the United States. Disaster Med Public Health Prep. https://doi.org/10.1017/ dmp. 2020.80

Bethel JW, Foreman AN, Burke SC (2011) Disaster Preparedness Among Medically Vulnerable Populations. Am J Prev Med 40(2):139-143. https://doi.org/10.1016/j.amepre.2010.10.020

Bose A (2011). Census of India, 2011. In Economic and Political Weekly (Vol. 46, Issue 4).

Carden A (2010) Emily Chamlee-Wright: The cultural and political economy of recovery: social learning in a post-disaster environment. Public Choice 145(3-4):581-583. https://doi.org/10.1007/ s11127-010-9668-8

Chattopadhyay S, Franke RW (2006) Striving for sustainability : Environmental stress and democratic initiatives in Kerala. Concept Publishing Co.

Crabbé P, Robin M (2006) Institutional adaptation of water resource infrastructures to climate change in Eastern Ontario. Clim Change 78(1):103-133. https://doi.org/10.1007/s10584-006-9087-5

CRED (2020) Natural disasters 2019: Now is the time to not give up. https://cred.be/sites/default/files/ adsr_2019.pdf 
Cutter SL, Tiefenbacher J, Solecki WD (1992) En-gendered fears: femininity and technological risk perception. Indu Crisis Q 6(1):5-22. https://doi.org/10.1177/108602669200600102

de Souza Briggs, X. (2004). Social capital: Easy beauty or meaningful resource? J Am Plan As 70(2)

Dooley D, Catalano R, Mishra S, Serxner S (1992) Earthquake preparedness: predictors in a community survey1. J Appl Soc Psychol 22(6):451-470. https://doi.org/10.1111/j.1559-1816.1992.tb00984.x

Dynes RR (2002) The Importance Of Social Capital In Disaster Response. Disaster Research Center. http://udspace.udel.edu/handle/19716/292

Dynes RR (2006) Social capital: dealing with community emergencies. Homeland Secur Aff 2(2):1-26

Eisenman DP, Zhou Q, Ong M, Asch S, Glik D, Long A (2009) Variations in disaster preparedness by mental health, perceived general health, and disability status. Disaster Med Public Health Prep 3(1):33-41. https://doi.org/10.1097/dmp.0b013e318193be89

Elliott JR, Haney TJ, Sams-Abiodun P (2010) Limits to social capital: comparing network assistance in two new Orleans Neighborhoods devastated by Hurricane Katrina. Sociol Q 51(4):624-648. https:// doi.org/10.1111/j.1533-8525.2010.01186.x

Ford JD, Smit B, Wandel J (2006) Vulnerability to climate change in the Arctic: a case study from Arctic Bay, Canada. Glob Environ Change 16(2):145-160. https://doi.org/10.1016/j.gloenvcha.2005.11. 007

Fothergill A (1996) Gender, risk and disaster. Int J Mass Emergencies Disasters 14(1):33-56

Fujii M, Kanbara S (2019) Analysis of gender differences in disaster preparedness for Nankai Trough Earthquake. Health Sci J 13(2):644. https://doi.org/10.36648/1791-809X.1000644

Hamidazada M, Cruz AM, Yokomatsu M (2019) Vulnerability factors of Afghan rural women to disasters. Int Jf Disaster Risk Sci 10(4):573-590. https://doi.org/10.1007/s13753-019-00227-z

Heller K, Alexander DB, Gatz M, Knight BG, Rose T (2005) Social and personal factors as predictors of earthquake preparation: the role of support provision, network discussion, negative affect, age, and education1. J Appl Soc Psychol 35(2):399-422. https://doi.org/10.1111/j.1559-1816.2005.tb02127.x

Henry S, Schoumaker B, Beauchemin C (2003) The Impact of \$\$in Burkina Faso. Popul Environ 25(5):423-460. https://doi.org/10.1023/b:poen.0000036928.17696.e8

Hyyppa MT (2003) Social participation and health in a community rich in stock of social capital. Health Educ Res 18(6):770-779. https://doi.org/10.1093/her/cyf044

Javadinejad S, Eslamian S, Ostad-Ali-Askari K (2021) The analysis of the most important climatic parameters affecting performance of crop variability in a changing climate. Int J Hydrol Sci Technol 11(1):1-25. https://doi.org/10.1504/IJHST.2021.112651

Koh HK, Cadigan RO (2008) Disaster preparedness and social capital. In: Social capital and health. Springer, New York, pp 273-285. https://doi.org/10.1007/978-0-387-71311-3_13

Kohn S, Eaton JL, Feroz S, Bainbridge AA, Hoolachan J, Barnett DJ (2012) Personal disaster preparedness: an integrative review of the literature. Disaster Med Public Health Prep 6(3):217-231. https:// doi.org/10.1001/dmp.2012.47

Lakkadi VRR (2013). Woman is family head now. Deccan Chronicle. https://www.deccanchronicle.com/ 131215/news-current-affairs/article/woman-family-head-now

Lam RPK, Leung LP, Balsari S, Hsiao K-H, Newnham E, Patrick K, Pham P, Leaning J (2017) Urban disaster preparedness of Hong Kong residents: a territory-wide survey. Int J Disaster Risk Reduction : IJDRR 23:62-69. https://doi.org/10.1016/j.ijdrr.2017.04.008

Lindell MK, Whitney DJ (2000) Correlates of household seismic hazard adjustment adoption. Risk Anal 20(1):13-26. https://doi.org/10.1111/0272-4332.00002

Lindström M, Hanson BS, Östergren P-O (2001) Socioeconomic differences in leisure-time physical activity: the role of social participation and social capital in shaping health related behaviour. Soc Sci Med 52(3):441-451. https://doi.org/10.1016/s0277-9536(00)00153-2

Liu W, Xu W, (Wayne), \& John, B. (2021) Organizational Disaster Communication Ecology: Examining Interagency Coordination on Social Media During the Onset of the COVID-19 Pandemic. Am Behav Sci 65(7):914-933. https://doi.org/10.1177/0002764221992823

Maier H, Klumb PL (2005) Social participation and survival at older ages: is the effect driven by activity content or context? Eur J Ageing 2(1):31-39. https://doi.org/10.1007/s10433-005-0018-5

Mathbor GM (2007) Enhancement of community preparedness for natural disasters. Int Soc Work 50(3):357-369. https://doi.org/10.1177/0020872807076049

McNeill CC, Killian TS, Moon Z, Way KA, Betsy Garrison ME (2018) The relationship between perceptions of emergency preparedness, disaster experience, health-care provider education, and emergency preparedness levels. Int Q Community Health Educ 38(4):233-243. https://doi.org/10.1177/ $0272684 \times 18781792$

Ministry of Earth Sciences, G. of I (2019) India Meteorological Department. https://mausam.imd.gov.in 
Ministry of Law and Justice (2013) THE NATIONAL FOOD SECURITY ACT, 2013. https://egazette.nic. in/writereaddata/2013/e_29_2013_429.pdf

Mitchell RC (1988) Waiting for disaster: earthquake watch in California. Ralph H. Turner , Joanne M. Nigg, Denise Heller Paz. Am J Sociol 94(1):219-220. https://doi.org/10.1086/228986

Mulilis J-P, Duval TS, Bovalino K (2000) Tornado preparedness of students, nonstudent renters, and nonstudent owners: issues of PrE Theory1. J Appl Soc Psychol 30(6):1310-1329. https://doi.org/10. 1111/j.1559-1816.2000.tb02522.x

Nakagawa Y, Shaw R (2004) Social capital: A missing link to disaster recovery. Int J Mass Emerg Disasters 22(1):5-34

Nations, U (2005) Hyogo Framework for Action (HFA) 2005-2015 building the resilience of nations and communities to disasters. United Nations (issue January). https://doi.org/10.1017/CBO9781107 415324.004

Nguyen HT (2018) Gendered vulnerabilities in times of natural disasters: male-to-female violence in the Philippines in the Aftermath of Super Typhoon Haiyan. Violence against Women 25(4):421-440. https://doi.org/10.1177/1077801218790701

O'Brien PW, Mileti D (1992) Citizen participation in emergency response following the Loma Prieta Earthquake. Int J Mass Emerg Disasters 10(1):71-89

Ostad-Ali-Askar K, Su R, Liu L (2018) Water resources and climate change. J Water Clim Change 9(2):239. https://doi.org/10.2166/wcc.2018.999

Ostad-Ali-Askari K, Ghorbanizadeh Kharazi H, Shayannejad M, Zareian MJ (2020) Effect of climate change on precipitation patterns in an arid region using GCM Models: Case Study of Isfahan-Borkhar Plain. Natural Hazards Rev. https://doi.org/10.1061/(asce)nh.1527-6996.0000367

Pelling M (1998) Participation, social capital and vulnerability to urban flooding in Guyana. J Int Dev 10(4):469-486. https://doi.org/10.1002/(sici)1099-1328(199806)10:4\%3c469::aid-jid539\%3e3.0. co;2-4

Perrow C (2007) The next catastrophe: reducing our vulnerabilities to natural, industrial, and terrorist disasters. Princeton University Press. https://doi.org/10.1515/9781400838516

Pickering CJ, O’Sullivan TL, Morris A, Mark C, McQuirk D, Chan EY, Guy E, Chan GK, Reddin K, Throp R, Tsuzuki S, Yeung T, Murray V (2018) The promotion of "Grab Bags" as a disaster risk reduction strategy. PLoS Currents. https://doi.org/10.1371/currents.dis.223ac4322834aa0bb0d6824ee424e7f8

Pourrostami K, Heshmat R, Hemati Z, Heidari-Beni M, Qorbani M, Motlagh ME, Raeisi A, Shafiee G, Ziaodini H, Beshtar S, Taheri M, Mahdavi-Gorabi A, Aminaei T, Kelishadi R (2020) Association of fruit and vegetable intake with meal skipping in children and adolescents: the CASPIAN-V study. Eat Weight Disord 25(4):903-910. https://doi.org/10.1007/s40519-019-00704-w

Putnam RD (1995a) Bowling alone: America's declining social capital. J Democr 6(1):65-78. https://doi. org/10.1353/jod.1995.0002

Putnam RD (1995b) Tuning in, tuning out: the strange disappearance of social capital in America. PS: Polit Sci Politics 28(04):664-683. https://doi.org/10.1017/s1049096500058856

Ranjit YS, Lachlan KA, Basaran A-MB, Snyder LB, Houston JB (2020) Needing to know about the crisis back home: Disaster information seeking and disaster media effects following the 2015 Nepal earthquake among Nepalis living outside of Nepal. Int J Disaster Risk Reduct 50:101725. https://doi.org/10. 1016/j.ijdrr.2020.101725

Rayamajhee V, Bohara AK (2021) Social capital, trust, and collective action in post-earthquake Nepal. Nat Hazards 105(2):1491-1519. https://doi.org/10.1007/s11069-020-04363-4

Rayamajhee V, Storr VH, Bohara AK (2021) Social entrepreneurship, co-production, and post-disaster recovery. Disasters. https://doi.org/10.1111/disa.12454

Reininger B, Alam S, Carrasco A, Chen Z, Adams B, McCormick J, Rahbar M (2013a) Intention to comply with mandatory hurricane evacuation orders among persons living along a coastal area-ERRATUM. Disaster Med Public Health Prep 7(1):111. https://doi.org/10.1017/dmp.2013.37

Reininger BM, Rahbar MH, Lee M, Chen Z, Alam SR, Pope J, Adams B (2013b) Social capital and disaster preparedness among low income Mexican Americans in a disaster prone area. Soc Sci Med 1982(83):50-60. https://doi.org/10.1016/j.socscimed.2013.01.037

Renzulli LA, Aldrich H, Moody J (2000) Family matters: gender, networks, and entrepreneurial outcomes. Soc Forces 79(2):523-546. https://doi.org/10.1093/sf/79.2.523

Riad JK, Norris FH, Ruback RB (1999) Predicting evacuation in two major disasters: risk perception, social influence, and access to resources1. J Appl Soc Psychol 29(5):918-934. https://doi.org/10.1111/j.15591816.1999.tb00132.x

Richey S (2007) Manufacturing Trust: Community Currencies and the creation of social capital. Polit Behav 29(1):69-88. https://doi.org/10.1007/s11109-007-9028-7 
Russell LA, Goltz JD, Bourque LB (1995) Preparedness and hazard mitigation actions before and after two earthquakes. Environ Behav 27(6):744-770. https://doi.org/10.1177/0013916595276002

Shaw R (2012) Chapter 1 overview of community-based disaster risk reduction. In: Community, environment and disaster risk management. Emerald Group Publishing Limited, pp 3-17. https://doi.org/10. $1108 / \mathrm{s} 2040-7262(2012) 0000010007$

Siri JG (2014) Independent associations of maternal education and household wealth with malaria risk in children. Ecol Soc. https://doi.org/10.5751/es-06134-190133

Striessnig E, Lutz W, Patt AG (2013) Effects of educational attainment on climate risk vulnerability. Ecol Soc. https://doi.org/10.5751/es-05252-180116

Talebmorad H, Abedi-Koupai J, Eslamian S, Mousavi SF, Akhavan S, Ostad-Ali-Askari K, Singh VP (2021) Evaluation of the impact of climate change on reference crop evapotranspiration in Hamedan-Bahar plain. Int J Hydrol Sci Technol 11(3):333-347. https://doi.org/10.1504/IJHST.2021.114554

Tanyag M (2018) Resilience, female altruism, and bodily autonomy: disaster-induced displacement in PostHaiyan Philippines. Signs: J Women in Cult Soc 43(3):563-585. https://doi.org/10.1086/695318

Teo M, Goonetilleke A, Ahankoob A, Deilami K, Lawie M (2018) Disaster awareness and information seeking behaviour among residents from low socioeconomic backgrounds. Int J Disaster Risk Reduct 31:1121-1131. https://doi.org/10.1016/j.ijdrr.2018.09.008

The World Bank (2018) Kerala Post Disaster Needs Assessment- Floods and Landslides August 2018

Tompkins EL (2005) Planning for climate change in small islands: Insights from national hurricane preparedness in the Cayman Islands. Glob Environ Chang 15(2):139-149. https://doi.org/10.1016/j.gloen vcha.2004.11.002

Uscher-Pines L, Hausman AJ, Powell S, DeMara P, Heake G, Hagen MG (2009) Disaster preparedness of households with special needs in Southeastern Pennsylvania. Am J Prev Med 37(3):227-230. https:// doi.org/10.1016/j.amepre.2009.04.028

Wamsler C, Brink E, Rantala O (2012) Climate change, adaptation, and formal education: the role of schooling for increasing societies' adaptive capacities in El Salvador and Brazil. Ecol Soc. https://doi. org/10.5751/es-04645-170202

Wilkinson B, Crampton E, Krupp J (2018) Recipe for disaster: building policy on shaky ground. The New Zealand Initiative

Wisner B, Adams J, Organization WH (2002) Health promotion and community participation. In: Wisner B, Adams J (eds) Environmental health in emergencies and disasters : a practical guide. World Health Organization, pp 202-215

Witvorapong N, Muttarak R, Pothisiri W (2015) Social participation and disaster risk reduction behaviors in Tsunami Prone Areas. PLoS ONE 10(7):e0130862-e0130862. https://doi.org/10.1371/journal.pone. 0130862

Yamamura E (2010) Effects of interactions among social capital, income and learning from experiences of natural disasters: a case study from Japan. Reg Stud 44(8):1019-1032. https://doi.org/10.1080/00343 400903365144

Yamamura E (2014) Natural disasters and social capital formation: the impact of the Great Hanshin-Awaji earthquake. Pap Reg Sci 95:S143-S164. https://doi.org/10.1111/pirs.12121

Publisher's Note Springer Nature remains neutral with regard to jurisdictional claims in published maps and institutional affiliations. 